\title{
AFLP-ANALYSIS OF VARIETAL POLYMORPHYSM IN Capsicum annuum L.
}

\author{
E.A. Snigir ${ }^{\text {1, } 2, \text { O.N. Pyshnaya }}{ }^{1}$, E.Z. Kochieva ${ }^{2}$, N.N. Ryzhova ${ }^{2}$ \\ ${ }^{1}$ All-Russian Research Institute of Breeding and Seed Production of Vegetable Crops, Russian Academy of Agricultural Sciences, \\ pos. VNIISSOK, Odintsovo Region, Moscow Province, 143080 Russia \\ e-mail: pishnaya o@mail.ru \\ ${ }^{2}$ Center "Bioengineering”, Russian Academy of Science, \\ 7/1, prosp. 60-letiya Oktyabrya, Moscow, 117312 Russia \\ e-mail: ekochieva@yandex.ru
}

Received May 12, 2012

S u m m a r y

\begin{abstract}
AFLP-system of multipoint marking was used for estimation of genetic diversity in 45 varieties of Capsicum annuum L. As a result, it was selected 8 primer combinations, which were the most informative for marking of paprika genome. Due to these primers the authors obtained the specific DNA-spectrums for each variety. In total, 956 polymorphous AFLP-fragments were detected, of which 182 fragments characterize the individual varietal genotypes. The calculated coefficients of intervarietal genetic diversity are varying from 0.005 to 0.064 . On dendrogram all varieties form general cluster with weak intrinsic differentiation that indicates the low degree of genetic polymorphism. So the forming of distance basal branches, revealed in closely related cultural species $\mathrm{C}$. frutescens, $C$. chinense and $C$. baccatum, reflects the potential of their genetic diversity which may be used in paprika breeding.
\end{abstract}

Keywords: Capsicum annuum, genetic diversity, genetic polymorphism, AFLP-markers.

Pepper (genus Capsicum) is one of major vegetable crops. Pepper fruits are appreciated for specific taste, high content of vitamins, dietary and nutritional value. C. annuum is the most common of five cultivated Capsicum species: its annual global production is about 27 million tons (1). In Russia pepper is grown in the southern regions (Krasnodar and Stavropol, Rostov) on the area of 10,9 hectares. High yields and production of pepper in open ground and greenhouses directly depend on assortment of grown cultivars. Therefore, the urgent task is creation of varieties and heterosis hybrids whose properties allow successful cultivation of this crop in Russia (2).

Today, breeding work has provided a huge assortment of $C$. annuum cultivar types distinguished mainly by features of fruits (shape, color, size, degree of pungency). However, it's still unclear how much this wide variety corresponds to real genetic polymorphism. Genetic composition of different cultivar types determined on features of fruits may be quite diverse, and genetically similar samples may belong to different groups (3). In this regard, the assessment of real genetic diversity of Capsicum and isolation of cultivar types based on peculiarities of their genomes can be especially important for effective use of their genetic resources in plant breeding, early detection of possible genetic erosion, revealing the origin of cultivated species and varieties with connection to agricultural history of particular regions $(4,5)$.

Plant breeders usually assess a potential diversity of the gene pool by phenotypic descriptors and/or biochemical markers. However, using this approach is complicated by polygenic nature of many phenotypic characters and their dependence on environmental conditions. Along with it, detailed phenotypic characterization of large collections is quite difficult. For this reason, DNA genotyping technology is becoming an indispensable complement to phenotypic description of varieties.

Modern genotyping of collections is based on several marker systems with different reproducibility, reliability, and efficiency - RFLP (restriction fragment length polymorphism), RAPD (random amplified polymorphic DNA), STS (sequence tagged sites), AFLP (amplified fragment length polymorphism), SSR (simple sequence repeat), SNP (single nucleotide polymorphism), and others that detect polymorphism in different regions of the genome. At the present time, the most popular fast and highly reproducible method is AFLP-analysis that operates with a large number (50-300) of polymorphic loci of predominantly selectively neutral nature, which are unique and moderately repetitive sequences (6). AFLP is widely used in analysis of population polymorphism, phylogenetic relations, identification of species, and labeling the loci linked to economically valuable traits (7-9). In breeding work, this method can be used for preliminary assessment of initial genetic material in order to plan strategy of crosses, detect best combinations of genotypes, and selection (9-11). The efficiency of AFLP was proved in studies of the genetic polymorphism of different objects, including cultivated plant species (12-14).

In this research, the authors assessed genetic diversity of Capsicum annuum cultivars most commonly utilized in domestic selection by means of a multilocus AFLP-analysis.

Technique. The object of study were 45 most widespread varieties of sweet pepper C. annuum of domestic breeding, including 28 varieties of VNIISOK (All-Russia Research and Development Institute of Vegetable Crop Selection and Seed Growing) and several well-known foreign varieties, as well as samples of three other cultivated species often involved in breeding of sweet pepper - C. frutescens, C. chinense, C. baccatum.

Isolation of total DNA and AFLP-labeling were performed according to standard procedures $(15,16)$. DNA of samples $(250$ ng) was hydrolyzed with restriction enzymes EcoRI and TruI, ligated with corresponding adapters ("Fermentas", Lithuania). PCR was conducted using a reagent kit ("Dialat LTD", Russia) in a thermocycler ("Applied Biosystems", USA). AFLP- labeling included two stages: first - pre-amplification with primers complementary to the restriction site and adapter sequence with a single complementary nucleotide on 3'-end, second - selective amplification with primers that had 2-3 complementary nucleotides on 3'-end (at this stage EcoRI-primers on 5'-end also contained infrared label IRD700 or IRD800). Resulting DNA fragments were separated in a 6\% polyacrylamide gel and visualized with a high-resolution system LI-COR 4300 DNA Analyzer (17).

Statistical analysis accounted only the data of clear reproducible fragments. The degree of polymorphism of amplified fragments of the genome was determined as the ratio: number of polymorphic fragments / total number of obtained fragments, expressed as a percentage. Polymorphic DNA fragments were considered as fragments detected not in all spectra of the analyzed samples. Molecular panels of AFLP-fragments for each primer/enzyme combination were documented in Microsoft Excel in the form of binary matrices $1 / 0$. Upon these spectra and matrices then were revealed cultivar-specific DNA markers and calculated coefficients 
of pairwise genetic similarities/differences $(18,19)$ between samples.

Statistical analysis of data, determining the coefficients of pairwise similarities/differences, and constructing phylogenetic trees were performed in Statistica v. 6.0 (20), PAUP 4.0b10 (21) and Treecon software (22).

Results. Selection of primer combinations revealing intervarietal polymorphism of C. annuum. Preliminary tests with two restriction enzymes (EcoRI, TruI), two corresponding adapters, and eight primers (Table 1) were conducted on a limited set of samples (5 varieties) to compare the efficiency of 18 combinations of primer/enzyme.

1. Adapters and primers for pre-amplification and selective amplification used at preliminary testing of Capsicum annuum cultivars

\begin{tabular}{|c|c|c|}
\hline Adapter/primer & Code & Nucleotide sequence \\
\hline \multicolumn{3}{|c|}{ Adapters } \\
\hline \multirow{2}{*}{ EcoRI-adapter } & & 5'-CTC GTA GAC TGC GTA CC-3' \\
\hline & & 3'-CAT CTG ACG CAT GGT TAA-5', \\
\hline \multirow[t]{3}{*}{ TruI-adapter } & & 5'-GAC GAT GAG TCC TGA G-3' \\
\hline & & 3'-TA CTC AGG ACT CAT-5' \\
\hline & \multicolumn{2}{|c|}{ Primers for pre-amplification } \\
\hline EcoRI-primer $+\mathrm{A}$ & $\mathrm{E}_{01}$ & 5'-GAC TGC GTA CCA ATT C + A-3' \\
\hline TruI-primer $+\mathrm{C}$ & $\mathrm{T}_{02}$ & 5'-GAT GAG TCC TGA GTA A + C-3' \\
\hline \multicolumn{3}{|c|}{ Primers for selective amplification } \\
\hline EcoRI- primer $+\mathrm{A}+\mathrm{ACA}$ & $\mathrm{E}_{35}$ & 5'-GAC TGC GTA CCA ATT C + ACA-3' \\
\hline EcoRI- primer $+\mathrm{A}+\mathrm{AGG}$ & $\mathrm{E}_{41}$ & 5'-GAC TGC GTA CCA ATT C + AGG-3' \\
\hline TruI- primer $+\mathrm{C}+\mathrm{ACT}$ & $\mathrm{T}_{38}$ & 5'-GAT GAG TCC TGA GTA A + ACT-3' \\
\hline TruI- primer $+\mathrm{C}+\mathrm{CGA}$ & $\mathrm{T}_{55}$ & 5'-GAT GAG TCC TGA GTA A + CGA-3' \\
\hline TruI- primer $+\mathrm{C}+\mathrm{CTA}$ & $\mathrm{T}_{59}$ & 5'-GAT GAG TCC TGA GTA A + CTA-3' \\
\hline TruI- primer $+\mathrm{C}+\mathrm{CTG}$ & $\mathrm{T}_{61}$ & 5'-GAT GAG TCC TGA GTA A + CTG-3' \\
\hline
\end{tabular}

A subsequent AFLP-analysis was performed using eight selected primer combinations that provided high-reproducible DNA spectra and detected intervarietal polymorphism (Table 2).

AFLP-analysis of pepper cultivars. The eight selected primer combinations were used to evaluate polymorphism in 48 samples of $C$. annuum including 45 cultivars of domestic and foreign breeding and three samples of closely related species $C$. frutescens, $C$. chinense, $C$. baccatum (Table 2). Total number of detected AFLP-fragments - 1009, including 956 fragments (94,8 \%) polymorphic for the whole set of samples and $182(45,5 \%)$ fragments associated with intervarietal polymorphism of $C$. annuum.

The length of fragments selected for the analysis ranged from 80 to $450 \mathrm{bp}$ (Fig. 1). The number of polymorphic fragments varied depending on a primer pair: for $C$. annuum - from 7 (for E-ACA/T-CTG) to 40 (for E-AGG/T-CTG), for C. annuum and related species $C$. frutescens, $C$. chinense, $C$. baccatum - from 97 (for E-ACA/T-CGA and E-AGG/T-CGA) to 151 (for E-AGG/TCTA). The average number of polymorphic fragments per primer pair for $C$. annuum cultivars was 22,75 , for the entire set of genotypes $-119,5$.

2. Characteristics of polymorphism in Capsicum annuum cultivars and Capsicum species revealed using the selected AFLP primers

\begin{tabular}{|c|c|c|c|c|c|c|}
\hline \multirow{3}{*}{\multicolumn{2}{|c|}{ Primer/enzyme (EcoRI/TruI) }} & \multicolumn{5}{|c|}{ Number of fragments } \\
\hline & & \multicolumn{4}{|c|}{ Amplified } & \multirow{3}{*}{$\begin{array}{l}\text { variety- } \\
\text { specific }\end{array}$} \\
\hline & & \multicolumn{2}{|c|}{ C. annuum } & \multicolumn{2}{|c|}{ C. annuum + Capsicum species } & \\
\hline $\begin{array}{l}\text { combina- } \\
\text { tion }\end{array}$ & selective nucleotides & total & $\begin{array}{l}\text { polymor- } \\
\text { phic (\%) }\end{array}$ & total & polymorphic (\%) & \\
\hline$\overline{\mathrm{E}_{35} / \mathrm{T}_{38}}$ & $\mathrm{EcoRI}+\mathrm{A}+\mathrm{ACA} / \mathrm{TruI}+\mathrm{C}+\mathrm{ACT}$ & 66 & $35(53,0)$ & 132 & $129(97,7)$ & 6 \\
\hline $\mathrm{E}_{41} / \mathrm{T}_{38}$ & $\mathrm{EcoRI}+\mathrm{A}+\mathrm{AGG} / \mathrm{TruI}+\mathrm{C}+\mathrm{ACT}$ & 64 & $36(56,3)$ & 139 & $133(95,7)$ & 14 \\
\hline $\mathrm{E}_{35} / \mathrm{T}_{55}$ & $\mathrm{EcoRI}+\mathrm{A}+\mathrm{ACA} / \mathrm{TruI}+\mathrm{C}+\mathrm{CGA}$ & 37 & $13(35,1)$ & 100 & $97(97,0)$ & 2 \\
\hline $\mathrm{E}_{41} / \mathrm{T}_{55}$ & $\mathrm{EcoRI}+\mathrm{A}+\mathrm{AGG} / \mathrm{TruI}+\mathrm{C}+\mathrm{CGA}$ & 39 & $15(38,5)$ & 102 & $97(95,1)$ & 6 \\
\hline $\mathrm{E}_{35} / \mathrm{T}_{59}$ & $\mathrm{EcoRI}+\mathrm{A}+\mathrm{ACA} / \mathrm{TruI}+\mathrm{C}+\mathrm{CTA}$ & 47 & $9(19,2)$ & 114 & $99(86,8)$ & 1 \\
\hline $\mathrm{E}_{41} / \mathrm{T}_{59}$ & $\mathrm{EcoRI}+\mathrm{A}+\mathrm{AGG} / \mathrm{TruI}+\mathrm{C}+\mathrm{CTA}$ & 55 & $27(49,1)$ & 155 & $151(97,4)$ & 6 \\
\hline $\mathrm{E}_{35} / \mathrm{T}_{61}$ & $\mathrm{EcoRI}+\mathrm{A}+\mathrm{ACA} / \mathrm{TruI}+\mathrm{C}+\mathrm{CTG}$ & 22 & $7(31,8)$ & 110 & $106(96,4)$ & 1 \\
\hline $\mathrm{E}_{41} / \mathrm{T}_{61}$ & $\mathrm{EcoRI}+\mathrm{A}+\mathrm{AGG} / \mathrm{TruI}+\mathrm{C}+\mathrm{CTG}$ & 70 & $40(57,1)$ & 157 & $144(91,7)$ & 6 \\
\hline Всего & & 400 & $182(45,5)$ & 1009 & $956(94,8)$ & 42 \\
\hline
\end{tabular}

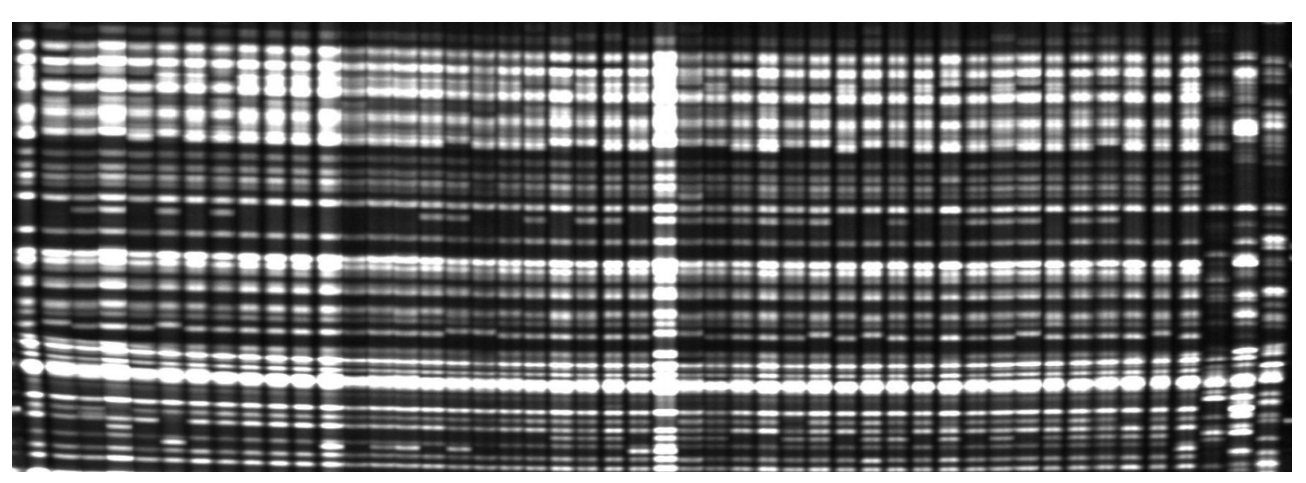

Fig. 1. AFLP-spectra of Capsicum species derived with the use of primer combination E-AGG/T-CTG (fragment of gel).

The most efficient detection of varietal polymorphism provided primer combinations E-AGG/T-CTG and E-ACA/T-ACT that detected, respectively, 57,1 and 53,0 \% polymorphic fragments. In the entire set of genotypes the most informative primer pairs were E-ACA/T-ACT and E-ACA/T-CTA: respectively, 97,7 and 86,8 \% of total revealed polymorphisms.

In the scientific literature it was repeatedly noted the impossibility of detecting a large number of polymorphic fragments in pepper cultivars by AFLP-labeling. E.g., I. Paran et al. (23) tested a set of 34 C. annuum cultivars of different origin with 10 primer pairs and obtained only $13 \%$ polymorphic fragments with about 6,5 polymorphic loci per primer pair. S. Tam et al. (24) studied 35 
genotypes of pepper with 9 primer pairs and detected only 8,03\% polymorphic fragments. Apparently, in the presented work the selected primers revealed unique cultivar-specific AFLP-fragments: 8 primer combinations identified 42 cultivar-specific fragments in 24 varieties and unique AFLP-spectra of each cultivar. The highest number of specific fragments was found in genomes of cultivars Pirati, Kaskad, Khrizolit, and Zlatozar. The identified cultivar-specific AFLP-fragments can be further modified into SCAR-markers (sequence characterized amplified regions) of these varieties.

Individual spectra of AFLP-fragments were obtained for each sample and 24 cultivars, however, the degree of intervarietal polymorphism was very low. The coefficient of genetic differences (GD) ranged from 0,005 (cv Mazurka and Purple Krasavitsa) to 0,064 (cv Kaskad and Medal), and the average was 0,037.

These results confirm the earlier findings of many authors who used RAPD and AFLP technique of multilocus labeling. I. Paran et al. (23) noted the extremely low (almost zero) genetic diversity in large-fruited pepper cultivars (Saxo, Capistrano, Jupiter, HA 789 , Reflex, Marvello). H. Aktas et al. (25) reported no significant differences between European large-fruited varieties. A slightly higher polymorphism was detected in local cultivars and samples from Turkey with genetic distance (GD) 0,079 , as well as in some small-fruited chili pepper cultivars of different origin $(\mathrm{GD}=0,070)(23,25)$.

Such small genetic polymorphism of the studied varieties may result from a limited genetic pool utilized in breeding largefruited sweet pepper, or it may reflect the conservative nature of the genome of cultivated C. annuum owing to self-pollination. It is known that varieties of another self-pollinated cultivated species - tomato Lycopersicon esculentum (26) - also show very small polymorphism in the genome. For tomato, a narrow genetic base has become a "bottleneck" of breeding (27-29) .

An interesting finding was significantly higher genetic differences (GD) between $C$. annuum cultivars and related species $C$. frutescens, $C$. chinense, $C$. baccatum (genetic distances, respectively, 0,43; 0,46;0,43). The close relatives $C$. annuum- $C$. frutescens$C$. chinense belong to one evolutionary and phylogenetic group of species, so the identified polymorphism suggests the presence of genetic potential that can be used in the breeding of modern varieties of $C$. annuum.

A similar potential of other closely related pepper species was described by K. Sanatombi et al. (5): GD = 0,2 between $C$. annuum cultivars, while $\mathrm{GD}=0,7$ between $C$. annuum and $C$. chinense.

The data on genetic polymorphism of studied cultivars and samples were used to construct a dendrogram reflecting similarity of these genotypes (Fig. 2). Along with it, each studied genotype was differentiated. The best results in differentiation of $C$. annuum genotypes were obtained using the primer combinations E41/T61, E41/T59, E41/T38, and E35/T38 that allowed identification of, respectively, 91, 82, 80, and 77\% studied genomes; using only two of these primer combinations differentiated genotypes of all 45 cultivars. As expected, basal position on the dendrogram takes C. baccatum (genetic complex baccatum). Cultivated representatives of the genetic complex annum $(C$. annuum, $C$. frutescens, $C$. shinense) form one cluster in which $C$. frutescens and $C$. chinense belong to one group (75\%), while $C$. annuum forms a separate low-polymorphic cluster (100\%).

In general, topology of the cluster $C$. annuum clearly reflected low genetic variability of sweet pepper cultivars and conservative genome of the analyzed samples of this species. Dendrogram illustrates the almost complete absence of any differentiation of groups within the cluster $C$. annuum, except a few small groups with a bootstrap index (B) more than $50 \%$ that included 2-3 cultivars. For example, the group with B $=57 \%$ was formed by two cultivars Izabella and Rodnik - descendants of a common ancestor Czech variety Rubin. 


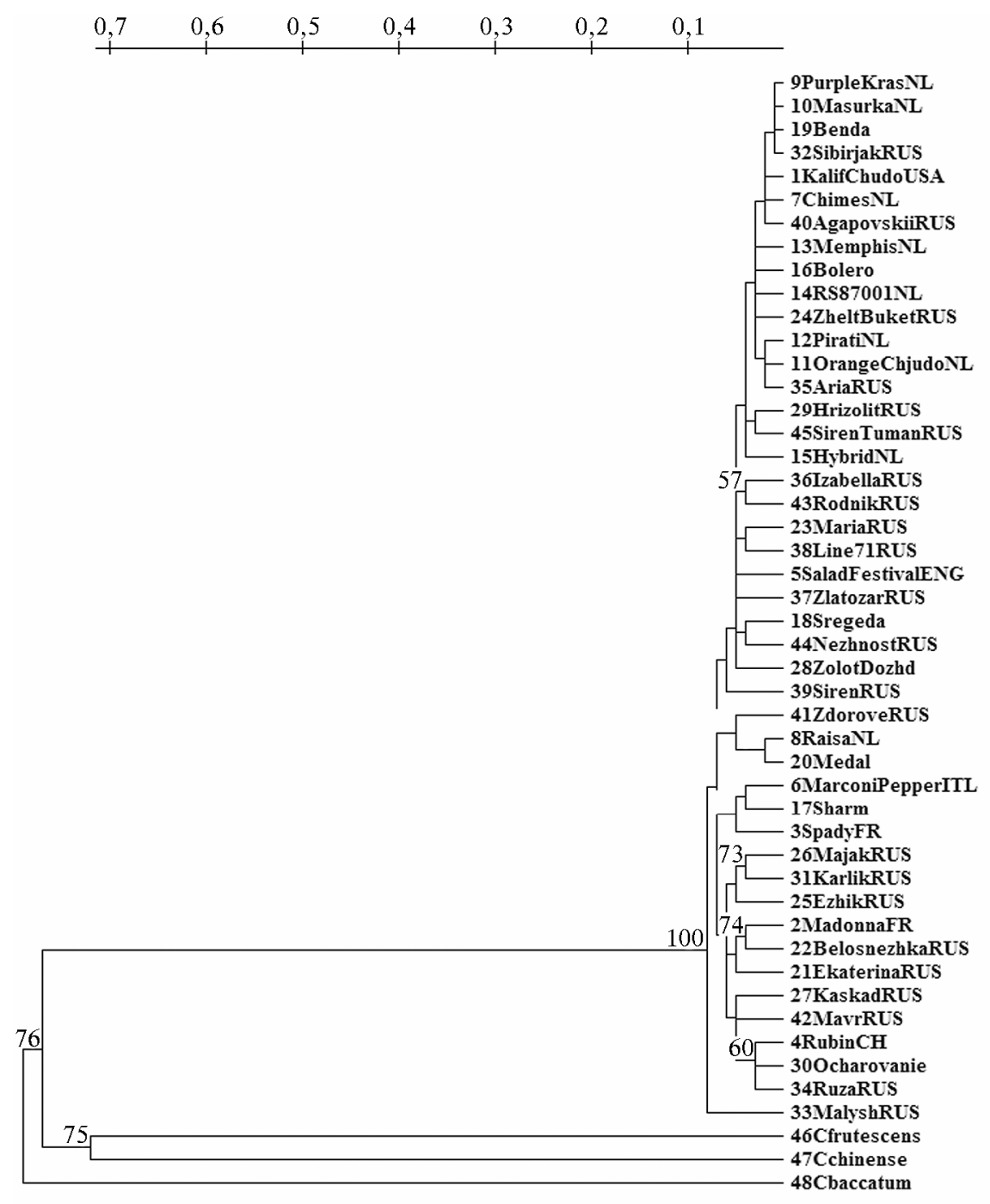

Fig. 2. Dendrogram of genetic differences (GD) between 48 studied genotypes of Capsicum constructed upon results of AFLP-analysis with 8 pairs of special selected primers: samples №№ $1-45-C$. annuum, 46, 47, and 48 - respectively, C. frutescens, C. chinense, and C. baccatum.

Another group with $\mathrm{B}=74 \%$ (cv Belosnezhka and Madonna) supposedly has in a pedigree a common variety Garden Sunshine. Similarly, the relationship of hybrids Ocharovanie, Ruza and parental cv Rubin was reflected by the cluster with B $=60 \%$. Cultivars Mayak and Karlik (cluster with $\mathrm{B}=73 \%$ ) are known to carry in their genomes an identical allelic variant of $f a$ gene (fasciculate location of fruits). The highest differences in the cluster $C$. annuum showed cv Malysh whose pedigree includes $C$. baccatum. In general, the degree of genetic differences between individual members of the cluster didn't exceed 0,1 .

Thus, it has been chosen a combination of AFLP-primers and enzymes that provides polymorphic DNA spectra of Capsicum annuum cultivars most commonly used in domestic breeding. Two of the proposed primer combinations can differentiate genotypes of all 45 investigated cultivars. Specific spectra of amplified fragments were obtained for 24 cultivars; these cultivar-specific fragments that can be converted into cultivar-specific monolocus DNA markers (SCAR-markers). The genome of $C$. annuum was found to be highly-conservative with a very low degree of genetic polymorphism. These facts suggest that a limited genetic basis of modern pepper need to be expanded and involve more polymorphic sources of economically useful traits from representatives of closely related wild and cultivated species (C. annuum, C. frutescens, $C$. shinense), samples from centers of origin, and other divergent local populations.

\section{REFERENCES}

1. FAO Production year book, 2010 (http://faostat.fao.org/).

2. Pyshnaya O.N. Nauchnoe obosnovanie sistemy metodov selektsii i semenovodstva pertsa sladkogo i ostrogo dlya srednei polosy Rossii. Avtoreferat doktorskoi dissertatsii [Scientific Bases for the System of Breeding Methods and Seed Growing of Vegetable and Spice Pepper in Midland Russia, Extended Abstract of Doctoral Sci. Dissertation]. Moskva, 2005.

3. Bosland P.W., Votava E.J. Peppers: Vegetable and spice Capsicums. Crops Production Science in Horticulture, 12. CABI Publishing, Wallingford, 2000.

4. Ortiz A., Cervantes P., Zlotnik P., Van de Velde C., Slaney C., Garnham J., Turecki G., O'Donovan C., Alda M. Cross-prevalence of migraine and bipolar disorder. Bipolar Disorder, 2010, 12: 397-403.

5. Sanatombi K., Sen-Mandi S., Sharma G.J. DNA profiling of Capsicum landraces of Manipur. Sci Hort, 2010, 124: 405-408.

6. Vos P., Hogers R., Bleeker M., Reijans M., Van de Lee T., Hornes M., Frijters A., Pot J., Peleman J., Kuiper M., Zabeau M. AFLP: a new technique for DNA fingerprinting. Nucl. Acids Res., 1995, 23: 4407-4414.

7. Renganayaki K., Read J.C., Fritz A.K. Genetic diversity among Texas bluegrass genotypes (Poa arachnifera Torr.) revealed by AFLP and RAPD markers. Theor. Appl. Genet., 2001, 102: 1037-1045.

8. Soleimani V.D., Baum B.R., Johnson D.A. Identification of Canadian durum wheat (Triticum turgidum L. subsp. durum (Desf) Husn.) cultivars using AFLP and their STS markers. Can. J. Plant Sci., 2002, 82: 35-41.

9. Kim P., Leckman J.F., Mayes L.C., Feldman R., Wang X., Swain J.E. The plasticity of human maternal brain: Longitudinal changes in brain anatomy during the early postpartum period. Behavioral Neuroscience, 2010, 124: 695-700.

10. Sensi E., Vignani R., Scali M., Masi E., Cresti M. DNA fingerprinting and genetic relatedness among cultivated of Oleaeuropaea L. estimated by AFLP analysis. Sci Hort., 2003, 97: 379-388. 
11. Portis E., Acquadro A., Comino C., Lanteri S. Effect of farmer's seed selection on genetic variation of landrace population of pepper (Capsicum annuum L.), grown in North-West Italy. Genet. Res. Crop Evol., 2004, 51: 581-590.

12. Wang F., Li F., Wang J., Zhou Y., Sun H. Genetic diversity of the selected 64 potato germplasms revealed by AFLP markers. Mol. Plant Breed., 2011, 12(4): 22-29. 13. Tümbilen Y., Frary A., Mutlu S., Doganlar S. Genetic diversity in Turkish eggplant (Solanum melongena) varieties as determined by morphological and molecular analyses. Int. Res. J .Biotechnol., 2011, 2(1): 16-25.

14. Akkale C., Yildirim Z., Yildirim M.B., Kaya C., Öztürk G., Bahattin T. Assessing genetic diversity of some potato (Solanum tuberosum L.) genotypes grown in Turkey using the AFLP marker technique. Turkish J. Field Crops, 2010, 15(1): 73-78.

15. Edwards K., Johnstone C., Thompson C. A simple and rapid method for the preparation of plant genomic DNA for PCR analysis. Nucl. Acid Res., 1991, 19(6): 1349 .

16. Snigir' E.A., Ryzhova N.N., Kochieva E.Z., Pyshnaya O.N. Sel'skokhozyaistvennaya Biologiya [Agricultural Biology], 2011, 6: 45-50 .

17. http://www.licor.com.

18. Jaccard P. Nouvelles rescherches sur la distribution florale. Bull. Soc. Vaud.Sci. Nat., 1908, 44: 223-270.

19. Nei M., Li W.H. Mathematical model for studying genetic variation in terms of restriction endonucleases. PNASUSA, 1979, 76: 5269-5273.

20. Statistica (Data Analysis Software System), version 6. StatSoft, Inc. 2001 (http://www.statsoft.com).

21. Swofford D.L. PAUP (and Other Methods). Phylogenetic analysis using parsimony. Sinauer Associates, Sunderland, Massachusetts, 2002

(http://www.sinauer.com/detail.php.id=8060).

22. Van de Peer Y., De Wachter R. Construction of evolutionary distance trees with TRE-ECON for Windows: accounting for variation in nucleotide substitution rate among sites. Comput. Applic. Biosci., 1997, 13: 227-230.

23. Paran I., Aftergoot E., Shifriss C. Variation in Capsicum annuum revealed by RAPD and AFLP markers. Euphytica, 1998, 99: 167-173.

24. Tam S.M., Mhiri C., Vogelaar A., Kerkveld M., Pearce S.R., Grandbastien M.A. Comparative analyses of genetic diversities within tomato and pepper collections detected by retrotransposon-based SSAP, AFLP and SSR. Theor. Appl. Genet., 2005, 110(5): 819-831.

25. Aktas H., Abak K., Sensoy S. Genetic diversity in some Turkish pepper (Capsicum annuum L.) genotypes revealed by AFLP analyses. African J. Biotechnol., 2009, 8(18): 4378-4386

26. Young H.P., Marilyn A.L., West M.A., St Clair D.A. Evaluation of AFLPs for germplasm fingerprinting and assessment of genetic diversity in cultivars of tomato (Lycopersicon esculentum L.). Genome, 2004, 47: 510-518.

27. Garcia-Martinez S., Andreani L., Garcia-Gusano M., Geuna F., Ruiz J.J. Evaluation of amplified fragment length polymorphism and simple sequence repeats for tomato germplasm fingerprinting: utility for grouping together closely related traditional cultivars. Genome, 2006, 49: 648-656.

28. Rajput S., Wable G.K.J., Sharma K.M., Kubde P.D., Mula S.A. Reproducibility testing of RAPD and SSR markers in tomato. African J. Biotechnol., 2006, 5: 108112.

29. Hiroaki E., Hiroyuki I., Tadashi T., Shigeru I. Genetic diversity of the «peruvianum-complex» (Lycopersicon peruvianum L. Mill. and L. chilense Dun.) revealed by RAPD analysis. Euphytica, 2000, 116: 23-31. 